\title{
The influence of pyrolysis temperature on lignite reaction kinetics and gas devolatilization process
}

\author{
Kai WANG ${ }^{a}$, Guangyao LIU ${ }^{b}$ \& Yang DONG \\ Huadian Electric Power Research Institute, Shandong Branch, No. 14800 Jing-shi Road, Lixia \\ district, Jinan, 250014, China \\ aandruwang@foxmail.com, b guangyao-liu@chder.com, cyang-dong@chder.com
}

\begin{abstract}
KEYWORD: Reaction kinetics; Devolatilization; Pyrolysis temperature; Lignite
ABSTRACT: Pyrolysis is a clean method for lignite utilization, and it is greatly influenced by temperature and heating rate. The reaction mechanism and kinetic model were investigated by means of Differential Thermal-Gravimetric Analyzer and Fourier Transform Infrared spectrometer. It is found that lower heating rate leads to prolonged reaction process and less residue mass, whereas higher heating rate causes more intense reaction rate with different devolatilization gas compositions. In addition, the generations of $\mathrm{CO} 2$ and $\mathrm{CO}$ have different functional groups resources and corresponding temperature ranges. The temperature range discrepancies are mainly caused by the organic functional groups diversity, which is produced when chemical bridge bonds between the adjacent structural element molecules crack. Finally the reaction kinetic parameters are given by test datum regression, and the reliable index indicates that the calculation is credible.
\end{abstract}

\section{INTRODUCTION}

Coal utilization is the No.1 fossil fuel consumption in China at present. Among plenty of coal types, lignite is classified into the young coal with low coalification degree, and it accounts for about $13 \%$ of the coal total reserves. Lignite is characterized by high volatile content, low caloric value, low mechanical strength and intense chemical reactivity, so it is difficult to be directly used either as combustion fuel or in chemical processing. Recently China pays more attention to lignite utilization with the price rise on thermal coal market.

Lignite pyrolysis is a clean method for coal utilization with various technologies, including fixed bed reactor, fluidized bed reactor and moving bed reactor with heat carrier (Zhou, Q. \& Zou, T. 2013). No matter which one is used, the pyrolysis process is significantly influenced by temperature and heating rate (Zou, L. et al. 2015, Canel, M. \& Wanzl, M. 1994). Therefore, the reaction kinetic parameters and mechanism are close related to pyrolysis temperature. In this work, these relations are investigated by means of Thermal / Differential Thermal-Gravimetric Analyzer (TG/DTG).

\section{TEST SYSTEM OF GAS DEVOLATILIZATION}

Figure 1 shows the schematic diagram of the test system for gas devolatilization. High-purity nitrogen is used for sweeping (flow rate is $50 \mathrm{ml} / \mathrm{min}$ ) and protection $(15 \mathrm{ml} / \mathrm{min}$ ). Besides, the quality change rate of reactant is measured by means of TG/DTG, which could report the kinetic parameters for pyrolysis reaction. In order to investigate the mechanism and process characteristic accurately, the Fourier transform infrared spectrometer (FTIR) is used to test the volatile gas composition. During the test, pyrolysis temperature ranges from 25 to $1100{ }^{\circ} \mathrm{C}$, and the heating rate are $5,10,20$ and $30^{\circ} \mathrm{C} / \mathrm{min}$, respectively. 


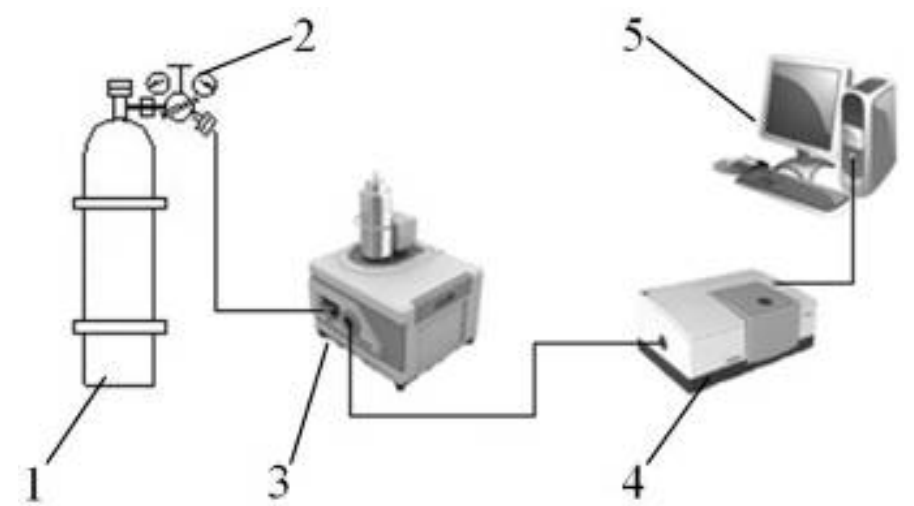

1-nitrogen gas cylinder, 2-flux control valve, 3-thermo gravimetric analyzer (TG/DTG), 4-infrared spectrometer, 5-data acquisition instrument.

Figure 1 Experimental system for gas devolatilization test

The lignite proximate and ultimate analysis is shown in Table 1, where M-moisture content, A-Ash content, V-volatile content, FC-fixed carbon content, LHV- low heat value, subscript ad-air dry basis. $\mathrm{C}, \mathrm{H}, \mathrm{O}, \mathrm{N}, \mathrm{S}$ are the element carbon, hydrogen, oxygen, nitrogen and sulfur respectively.

Table 1 Lignite composition analysis

\begin{tabular}{lllc}
\multicolumn{2}{l}{ Proximate analysis } & \multicolumn{2}{l}{ Ultimate analysis (\%) } \\
\hline $\mathrm{M}_{\mathrm{ad}}(\%)$ & 7.95 & $\mathrm{C}_{\mathrm{ad}}$ & 52.69 \\
$\mathrm{~A}_{\mathrm{ad}}(\%)$ & 18.46 & $\mathrm{H}_{\mathrm{ad}}$ & 4.27 \\
$\mathrm{~V}_{\mathrm{ad}}(\%)$ & 45.23 & $\mathrm{O}_{\mathrm{ad}}$ & 14.53 \\
$\mathrm{FC}_{\mathrm{ad}}(\%)$ & 28.36 & $\mathrm{~N}_{\mathrm{ad}}$ & 1.92 \\
$\mathrm{LHV}_{\mathrm{ad}}(\mathrm{MJ} / \mathrm{kg})$ & 16.4 & $\mathrm{~S}_{\mathrm{ad}}$ & 0.14 \\
\hline
\end{tabular}

\section{TEST RESULTS AND DISCUSSIONS}

The TG/DTG pyrolysis curves are shown in Figure 2, in which the lignite mass reduction rate changes with temperature and heating rate $\beta$. It can be seen that the residue mass rises when $\beta$ decreases and this phenomenon is more distinct when temperature exceeds $700{ }^{\circ} \mathrm{C}$. This is caused by prolonged reaction process for lower heating rate. Condensation react account for most pyrolysis reactions over $700{ }^{\circ} \mathrm{C}$, which transforms semi-coke into coke, and it is not as intense as volatile separate out from lignite. Hence, this kind of reaction requires more reaction time. In addition, Figure 2 indicates that higher heating rate leads to more intense reaction rate. There are two peaks on DTG curves; the first one appearing around $100{ }^{\circ} \mathrm{C}$ is caused by inherent water evaporation. On the contrary, volatile separates out from lignite give rise to the second peak that appears around $300 \sim 600{ }^{\circ} \mathrm{C}$, so the second peak indicates the most intense reaction temperature range.

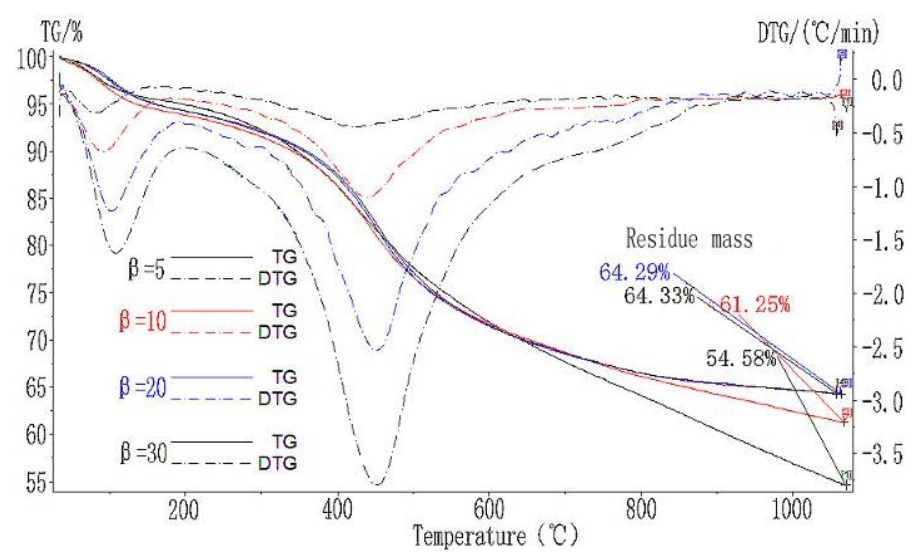

Figure 2 TG/DTG pyrolysis curves for different heating rate 
Figure 3 gives the three-dimensional characteristic chart of gas devolatilization at various heating rate. Where $\mathrm{X}$ axis is wave number which indicates the spectral band frequency $\left(\mathrm{cm}^{-1}\right), Y$ axis is absorbance that indicates the concentration for different gas composition, and $\mathrm{Z}$ axis is pyrolysis temperature $(\mathrm{K})$. It can be seen that $\beta$ has great effect on the gas devolatilization process and gas compositions. The absorbance units achieve climax when wave number is around 2200 and $2800 \mathrm{~cm}^{-1}$.

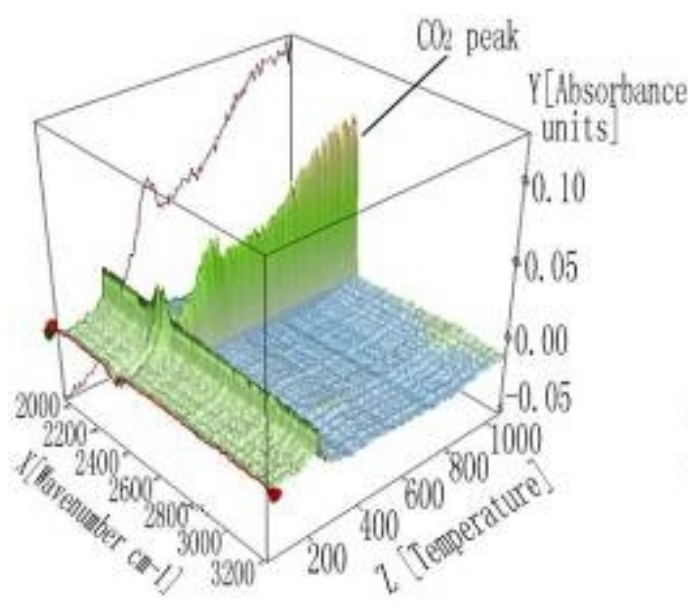

(a) $\beta=5^{\circ} \mathrm{C} / \mathrm{min}$

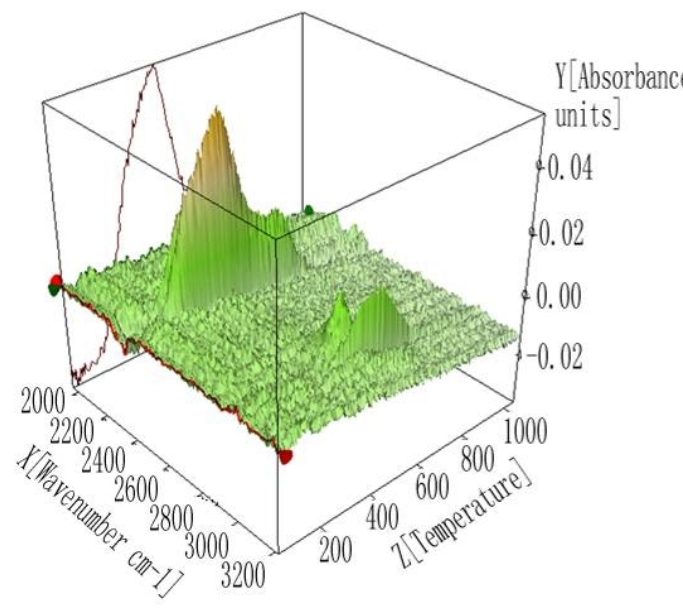

(c) $\beta=20^{\circ} \mathrm{C} / \mathrm{min}$

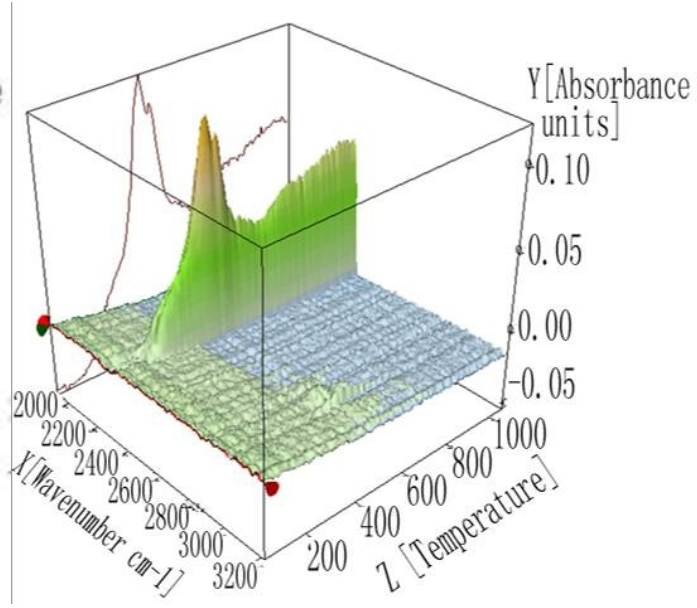

(b) $\beta=10^{\circ} \mathrm{C} / \mathrm{min}$

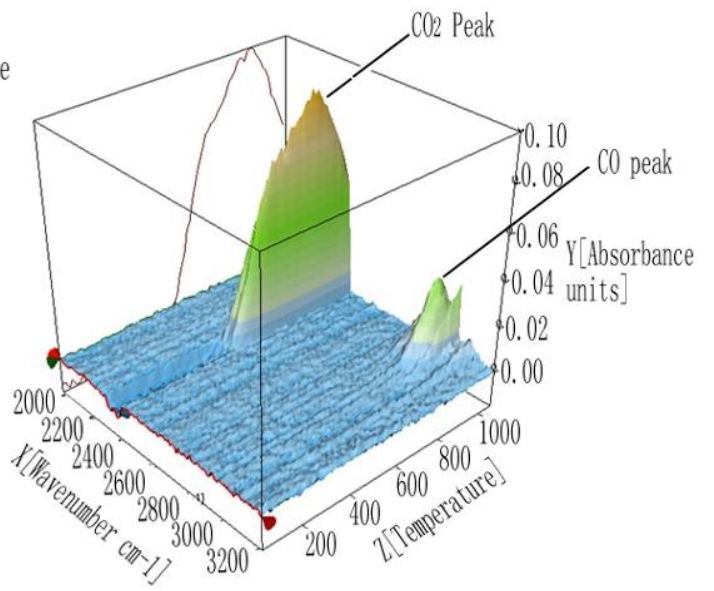

(d) $\beta=30^{\circ} \mathrm{C} / \mathrm{min}$

Figure 3 3D characteristic chart of gas devolatilization

Besides, separation rate of $\mathrm{CO}_{2}$ out of lignite reaches climax when pyrolysis temperature is around $300 \sim 600{ }^{\circ} \mathrm{C}$. In comparison, the maximum separation rate of $\mathrm{CO}$ from lignite appears when temperature ranges from $600 \sim 800{ }^{\circ} \mathrm{C}$. The temperature range discrepancies for $\mathrm{CO}_{2}$ and $\mathrm{CO}$ acute devolatilization are caused by the organic functional groups diversity, which is produced when chemical bridge bonds between the adjacent structural element molecules crack (Chu, M. et al. 2012, Gonzalez, J.A. 2012). As to $\mathrm{CO}_{2}$, it is generated by carboxyl functional groups (-COOH) break-up given in Equation (1) and Equation (2). Whereas $\mathrm{CO}$ is produced by carbonyl functional groups $(\mathrm{C}=\mathrm{O})$ break-up given in Equation (3). $\mathrm{R}$ denotes aromatic nucleus compositions in lignite.

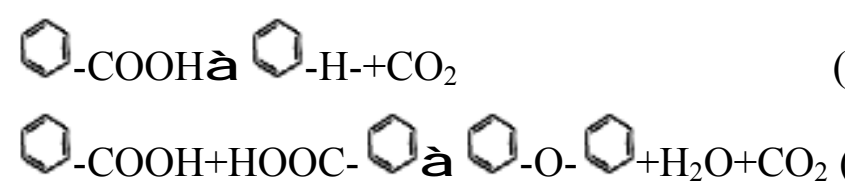




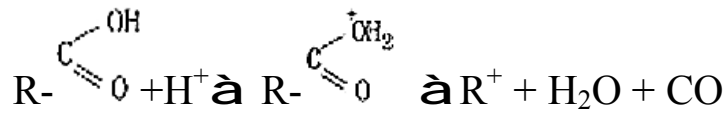

\section{KINETIC MODEL AND ITS PARAMETERS}

The pyrolysis process is assumed to be composed of $n$ stage reaction, where $n$ is positive integer (Tia, S. et al. 1991). Its reaction kinetic model is described in Equation (4). The pyrolysis kinetic equation (5) could be deduced by performing logarithm on both sides of Equation (4) (Vamvuka, D. et al. 2003).

$$
\begin{aligned}
& \mathrm{d} x / \mathrm{d} t=A \cdot \mathrm{e}^{-E /(R T)} \cdot(1-x)^{\mathrm{n}} \\
& \ln \left[\frac{1-(1-x)^{1-\mathrm{n}}}{T^{2}(1-n)}\right]=\ln \left[\frac{A R}{\beta E}\left(1-\frac{2 R T}{E}\right)\right]-\frac{E}{R T}
\end{aligned}
$$

Where $x$-mass ratio of residue to original lignite; $t$-time, second; A-frequency factor; $E$-activation energy, $\mathrm{kJ} / \mathrm{kmol} ; R$-universal gas constant, $8.314 \mathrm{~kJ} /(\mathrm{kmol} \cdot \mathrm{K}) ; T$-temperature, $\mathrm{K} ; \beta$-heating rate, ${ }^{\circ} \mathrm{C} / \mathrm{min}$; n-reaction stage number. Parameters $E$ and $A$ could be calculated by means of linear regression from Equation (5). Figure 4 shows the regression curves of kinetic parameters when heating rate is 5 and $30{ }^{\circ} \mathrm{C} / \mathrm{min}$, respectively, where the reaction stage number $\mathrm{n}$ is assigned with value 2 and 3. Besides, the exact reaction kinetic parameters regressed from Equation (5) is given in Table 2 and Table 3, where $\mathrm{k}$ and a are the slope and intercept of regression curve in Figure 4, respectively, $\mathrm{R}^{2}$ is reliable index.

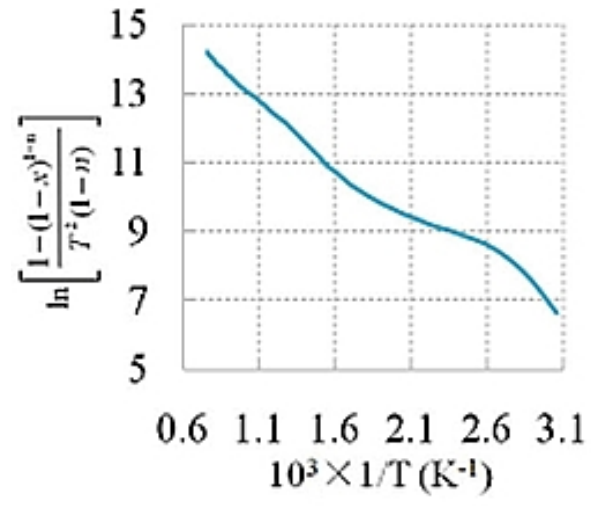

(a) $\beta=5, \mathrm{n}=2$

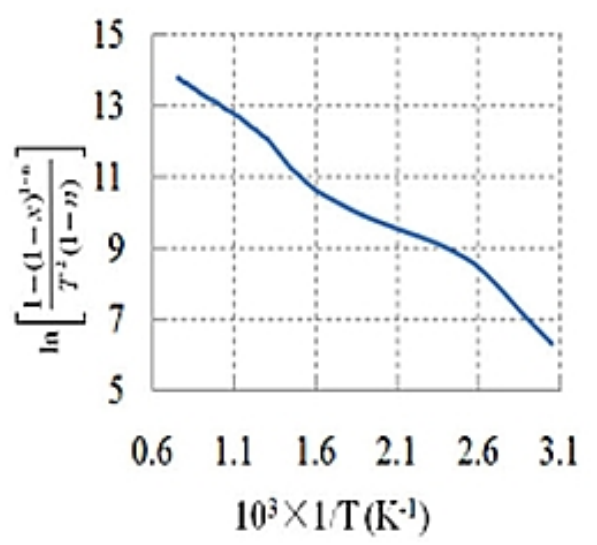

(c) $\beta=30, \mathrm{n}=2$

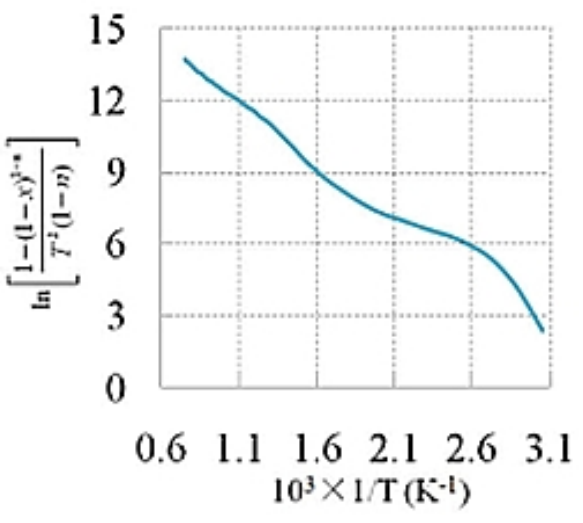

(b) $\beta=5, \mathrm{n}=3$

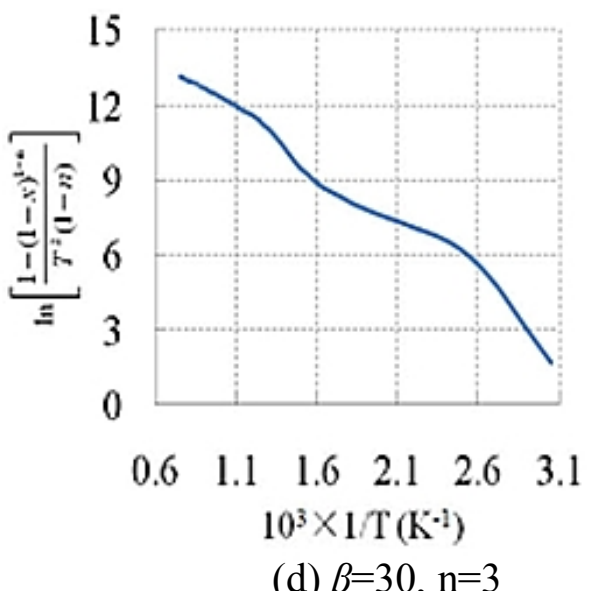

(d) $\beta=30, \mathrm{n}=3$

Figure 4 Regression curves of reaction kinetic parameters 
The calculation results given in Table 2 and Table 3 indicate that the activation energy for three stage reaction, namely $n=3$, is slightly higher than that of two stage reaction. Both of two kinetic models' results show that activation energy $E$ gradually increases with heating rate $\beta$ increment, and $E$ is around its peak when reaction temperature $T$ ranges from 300 to $600{ }^{\circ} \mathrm{C}$. Hence, the reaction is also intense in this temperature range that is shown in Figure 2.

Table 2 Reaction kinetic parameters when $\beta=5{ }^{\circ} \mathrm{C} / \mathrm{min}$

\begin{tabular}{llllllll}
\hline \multirow{2}{*}{ No. } & \multirow{2}{*}{ Items } & \multicolumn{2}{c}{$T=20 \sim 300^{\circ} \mathrm{C}$} & \multicolumn{2}{l}{$T=300 \sim 600^{\circ} \mathrm{C}$} & \multicolumn{2}{l}{$T=600 \sim 1100^{\circ} \mathrm{C}$} \\
& & $\mathrm{n}=2$ & $\mathrm{n}=3$ & $\mathrm{n}=2$ & $\mathrm{n}=3$ & $\mathrm{n}=2$ & $\mathrm{n}=3$ \\
\hline 1 & $\mathrm{k}$ & 2346 & 3745 & 4183 & 6160 & 4023 & 4888 \\
2 & $\mathrm{a}$ & 14.38 & 15.02 & 17.43 & 18.94 & 17.15 & 17.33 \\
3 & $\mathrm{R}^{\llcorner}$ & 0.946 & 0.913 & 0.998 & 0.997 & 0.996 & 0.997 \\
4 & $\begin{array}{l}E(\mathrm{~kJ} / \\
\text { mol) }\end{array}$ & 19.5 & 31.1 & 34.8 & 51.2 & 33.4 & 40.6 \\
& $\begin{array}{l}A(\times \\
5\end{array}$ & 15.4 & 11.3 & 1.13 & 0.34 & 1.46 & 1.43 \\
\hline
\end{tabular}

Table 3 Reaction kinetic parameters when $\beta=30{ }^{\circ} \mathrm{C} / \mathrm{min}$

\begin{tabular}{llllllll}
\hline \multirow{2}{*}{ No. } & \multirow{2}{*}{ Items } & \multicolumn{2}{c}{$T=20 \sim 300^{\circ} \mathrm{C}$} & \multicolumn{2}{c}{$T=300 \sim 600^{\circ} \mathrm{C}$} & \multicolumn{2}{c}{$T=600 \sim 1100^{\circ} \mathrm{C}$} \\
& $\mathrm{n}=2$ & $\mathrm{n}=3$ & $\mathrm{n}=2$ & $\mathrm{n}=3$ & $\mathrm{n}=2$ & $\mathrm{n}=3$ \\
\hline 1 & $\mathrm{k}$ & 2777 & 4586 & 4407 & 6545 & 2962 & 3366 \\
2 & $\mathrm{a}$ & 15.34 & 16.87 & 17.72 & 19.43 & 16.02 & 15.70 \\
3 & $\mathrm{R}^{\llcorner}$ & 0.945 & 0.915 & 0.992 & 0.991 & 0.999 & 0.998 \\
4 & $E(\mathrm{~kJ} /$ & 23.1 & 38.1 & 36.6 & 54.4 & 24.6 & 28.0 \\
& mol) & & & & & & \\
5 & $A(\times$ & 39.6 & 12.6 & 5.3 & 1.3 & 21.7 & 32.7 \\
\hline
\end{tabular}

\section{CONCLUSIONS}

The lignite pyrolysis reaction mechanism was investigated and its reaction kinetic procession was tested. It is found that pyrolysis temperature and heating rate have great effect on reaction rate and devolatilization gas compositions. Higher heating rate leads to more intense reaction rate, and the most acute reaction temperature range is $300 \sim 600{ }^{\circ} \mathrm{C}$, in which reaction rate arrives at its climax. In addition, $\mathrm{CO}_{2}$ is generated by carboxyl functional groups break-up in $300 \sim 600{ }^{\circ} \mathrm{C}$, whereas $\mathrm{CO}$ is produced by carbonyl functional groups crack within $600 \sim 800{ }^{\circ} \mathrm{C}$ in contrast. Finally the pyrolysis kinetic parameters were calculated from curve regressions. The results show that activation energy gradually increases with heating rate increment, and it is around the peak corresponding to the acute reaction temperature range.

\section{REFERENCES}

[1] Canel, M. \& Wanzl, M. 1994. Pyrolysis of a Turkish lignite at high heating rates. Fuel 73 (1): 137-138.

[2] Chu, M. Zhu, S.F. \& Yi, Y.Y. et al. 2012. Characteristics of pyrolysis products of Bori lignite briquette. Energy Procedia 16: 307-313.

[3] Gonzalez, J.A. Chabbi, A. \& Rosa, J.M. 2012. Evolution of organic matter in lignite-containing sediments revealed by analytical pyrolysis (Py-GC-MS). Organic Geochemistry 53: 119-130.

[4] Tia, S. Bhattacharya, S.C. \& Wibulswas, P. 1991. Thermogravimetric analysis of Thai lignite pyrolysis kinetics. Energy Conversion and Management 31 (3): 265-276.

[5] Vamvuka, D. Kakaras, E. \& Kastanaki, E. et al. 2003. Pyrolysis characteristics and kinetics of biomass residuals mixtures with lignite. Fuel 82 (15-17): 1949-1960.

[6] Zhou, Q. Zou, T. \& Zhong, M. et al. 2013. Lignite upgrading by multi-stage fluidized bed pyrolysis. Fuel Processing Technology 116: 35-43.

[7] Zou, L. Jin, L.J. \& Wang, X.L. et al. 2015. Pyrolysis of Huolinhe lignite extract by in-situ pyrolysis-time of flight mass spectrometry. Fuel Processing Technology 135: 52-59. 